THURSDAY, MAY II, I87I

\section{THE PROPOSED COLLEGE OF PHYSTCAL SCIENCE AT NEWCASTLE-UPON-TYNE}

$\triangle$ FEW weeks ago* we gave some account of the A initiation of a movement in the North of England, having for its object the establishment of a College of Physical Science in Newcastle-upon-Tyne. As the Executive Committee appointed at the public meeting had only then begun its work, the details entered upon were given as mere indications of the general form the institution might be expected to take. A letter from the Master of University College, Durham, which appeared in our columns more recently, added somewhat to our information, and a circular which has been issued, with commendable promptitude, by the Executive, is now before us, representing the views of the promoters as modified in committee.

We shall probabiy best further the intentions of the Committee, whom we are anxious to aid, and at the same time give our readers the most reliab!e information, if we reprint this document verbatim :-

"It is proposed to found at Newcastle-upon.Tyne, in connection with the University of Durham, a College for the teaching of Physical Science, especially as applied to Engineering, Mining, Manufactures, and Agriculture.

"The want of such an Institution has Iong been felt in the North of England, and it is believed that while it would be useful in all the above pursuits, it would be of especial value to all persons intended for the professions of Mining and Engineering.

"Such an Institution (which it appears desirable to limit at its commencement to purely scientific objects) would offer instruction in the following branches of scientific knowledge. I. Pure and Applied Mathematics. 2. Chemistry. 3. Experimental Philosophy. 4. Geology, Mineralogy, and Biology. Professorships and Lectureships will be founded on these subjects. It is proposed that the course of study shall last for two years, that it shall consist partly in attending lectures and partly in the work of the laboratories, that there shall be examinations at the end of each year, conducted mainly by Examiners from the Universities, and that at the final examination the successful students shall receive the title of Bachelor or Associate of Science of the University of Durham, or, upon certain further conditions, the degree of B.A. It is hoped that classes of evening lectures for those who are unable to attend during the day may soon be formed.

"The Government of the Institution will be entrusted to a Council, of which one-third will be nominated by the University of Durham. The University has offered the sum of I,oool. annually towards the establishment of Professorships and of ten Scholarships of $20 l$. each to assist students. It is believed that $2,000 l$. a-year is the lowest estimate at which it is possible to place the expenses of such a College, even at its commencement, and it is proposed to appeal to the public for a subscription to create a capital fund of at least 30,000 . If this amount be collected, the endowment from the University of Durham will be made a permanent one. When it is remembered that such an Institution will benefit a very large portion of the population of the Northern Counties, and be directly useful to nearly all branches of Manufacturing and Agricultural, as well as of Mining and Engineering pursuits, it is believed that no difficulty will be found in ultimately raising this sum, which, according to the experience of all similar institutions, will probably be increased by private donations both for Scholarships and Professor-

$$
\text { * See Nature, vol. iii. p. } 46 \text { I. }
$$

VOL. IV, ships. It is proposed to offer Subscribers the option either of paying their whole subscription at once or of extending it over a period of five or six years. Small as well as large subscriptions are invited towards the above. mentioned fund. Upwards of $100,000 \%$. has been recently collected in a similar case, or is in the course of collection, in subscriptions ranging from $2,000 l$. to the very smallest sums."

The last paragraph pleases us most. Six years is perhaps long enough to look forward in arrangements of many sorts, but not in matters pertaining to finance. The adoption of a scheme such as that originally suggested, based on a preliminary terminable endowment, would have crippled the energies of the whole staff, by suggesting the possibility of the early demolition of the structure they were labouring to build. It can scarcely be known, until the trial is made, how much may have to be done in the way of creating the demand for scientific education in the locality. We do not for a moment doubt its existence to a considerable extent, but we cannot suppose that the present case will form any exception to the general rule, that educational facilities are only slowly and by degrees taken advantage of by the classes for whose benefit they have been primarily designed. If the proposed college begins to find an appreciative public, and to promise eventual success within the six years, we should regard it as a subject of congratulation, and a proof alike of energy and judgment in its management, rather than as a matter of course. Happily, for this reason, the guarantee principle is to be put upon its best basis-funded property. Instead of $1,003 \%$ per annum for a term of six years, as at first proposed, the public is asked for $30,000 l$. in one sum. This, with the consequent permanent endowm nt from Durham University, which may be regarded as equal to another $30,000 \%$. capitalised, will provide a substantial foundation to commence upon. Nor can we doubt that the amount required will be easily raised amongst the wealthy men of the North.

We may perhaps say one word more about the selection of subjects for professorships, as our former remarks are alluded to in the Rev. Mr. Waite's letter.

We adverted to the absence of any mention of Biology as a part of the scheme of education in the report of the speech of the Dean of Durham at the preliminary meeting. In the revised programme, above reprinted, biology is not omitted, but that is all that can be said. The subject is tacked on to geology and mineralogy, and the result is a complete anomaly. To teach mineralogy in any modern sense, a man must be more than an average chemisthence no one who is not an expert in geology, mineralogy, chemistry, zoology, and botany, will have the requisite qualifications for the chair which it is now proposed to constitute. We trust that the Committee are prepared to pay pretty smartly for so handsome an instalment of omniscience. Our fear that biology of itself might be thought too large a subject for a single professorship, was at any rate groundless, but we doubt whether entire exclusion would be worse than the grant of a third of a chair.

The geological knowledge of first importance in a mining district is essentially "stratigraphical," in other words, that attained by practical field work. Just so much palæontology is necessary as will enable the student to recognise the more common characteristic fossils, and sufficient acquaintance with minerals to render him fami- 
liar with ordinary rock specimens. It would be better that Geology of this sort should be associated with a subject like mining, instead of being placed in the position it at present occupies.

Mineralogy, in any right sense, is only applied chemistry, and would be more in place as a recognised portion of the chemical curriculum in such an Institution than as a part of geology. Few geologists pretend to mineralogy beyond a sufficient knowledge of the general external characters of rocks for the recognition of the commoner varieties. Palæontology, on the other hand, as a subject of systematic study, is but a phase of biology, and cannot without violence be linked with subjects arising out of the laws which govern the inorganic world.

In thus eniarging upon our former remarks, we are actuated solely by a desire for the success of an undertaking which has our entire sympathy.

Just as we are going to press we learn that it has been determined to push forward the arrangements so as to enable the College to open its doors in October. This is a wise decision on many grounds. The first week in October has become the recognised time for the commencement of winter courses of lectures, and delay beyond that might easily entail the loss of a whole year. Of the $30,000 \%$ required, upwards of $17,000 \%$ has already been subscribed, without any systematic canvass, and we can scarcely doubt that the remainder will be forthcoming. On public grounds we would venture earnestly to second the appeal made by the Committee, and to express the hope that the liberality of the coal-owners, manufacturers, and merchants of the district will enable them to open the Institution free from pecuniary embarrassment, and clear of the manifold difficulties that beset an undertaking burdened at the outset with debt. We also hear at the same moment that the Committee has again debated the question of a biological professorship. That body seems to be undecided as to whether it would be less ridiculous to ignore biology entirely, or to include it with a number of quite distinct branches of science in a sort of miscellancous professorship, and the prevailing view now seems to be that, on the whole, the former alternative is the least conspicuously absurd. Surely there is a third course open to the Committee. We trust wiser counsels will prevail, and that we may never have to record that in Newcastle-the home of Bewick and Selby, Fryer and Alder, Winch and Robertson, not to name a host of living biologists - in the focus of the Tyneside Naturalists' Field Club-a College of Natural Science has been established in which Natural History in its higher aspects is excluded as a subject of study.

\section{STAVELEY'S BRITISH INSECTS}

British Insects. A familiar Description of the Form, Structure, Habits, and Transformations of Insecis. By E. F. Staveley, Author of "British Spiders." (London: L. Reeve and Co., I87I.)

TO compose a work on so extensive and difficult a subject as "British Insects," which shall convey a large amount of useful and interesting information without being too much overloaded with bare facts,- which shall be accurate without being dry, and amusing without being flippant,-is no easy task, yet it is accomplished by the author of this work in a very creditable manner. The introductory chapters are condensed and clear, just giving enough information on the general structure and economy of insects to interest the uninitiated reader, and lead him on to the more detailed account of each order given in the succeeding chapters.

An excellent feature of the work is the clearness of the type, and the well-executed woodcuts which somewhat too sparingly illustrate the text, while sixteen coloured plates by Mr. Robinson contain admirably life-like portraits of nearly a hundred of our most conspicuous or most interesting insects. A few extracts will best illustrate the author's style. In the chapter on the larva of Lepidoptera it is remarked, that there is neither time nor place in which we may not find the traces of these creatures or the creatures themselves.

"If at one time of the year we tear a handful of moss from the trunk of a tree, out drop some little brown chrysalids; if at another we drag a tuft of grass up by the roots, there we find silken tubes, the homes of some small caterpillars. We find them in fungi, we find them in grain, we find them in teazle-heads, in fir-cones, in rosebuds, and in fruit; and the Hymenopterist, carefully watching the insect emerging from a gall, discovers that he has reared in it a moth! On the face of a lichencovered rock we see a moving fragment, and lo! a little caterpillar, neatly encased like a caddis-worm in a tent of lichen, is moving and feeding, safe even from the lird's sharp eye. We open our drawers, and there, oh, sight of horror! What is that streak of white silk upon the best garment-the garment laid by, too good for common wear? We look farther; what is that dusty little roll? It is a great-coat on a microscopic scale. It matches our best garment ominously. It moves-a head peeps out-some little legs, and away it walks ! - tell not the housekeeper !away it walks in safety from the admiring Entomologist."

As an example of the woodcut illustrations we give the series showing the progressive stages in the transformations of the dragon-fly. The sluggish mud-coloured pupa ascends the stem of a grass or any other stalk of convenient size which rises above the surface of the vater, after a time the skin cracks behind, between the wing cases, and the head and thorax of the enclosed fly are drawn out. The abdomen follows, the insect turning up and clinging to the pupa case, where it remains till the wings increase to the full size so rapidly that they can be seen to grow.

In the chapter on Diptera there are some good remarks on the many erroneous uses of the term "Fly."

"Being a "popular name' the people have a right to mean what they choose by it, and they avail themselves of the right-some meaning by it one thing, some another, some every flying insect for which they know no other name. Thus the "fly' of the former is usually the little hopping turnip beetle; the 'fly' of the hop-grower is an aphis; the ' $\mathrm{fly}$ ' of the herdsman a gad; whlle to the citizen almost anything to be seen with wings (except pigeons and sparrows) is a fly. There are some, again, to whom flies are fies, one fly the fly, the common well-known little black house-fly. Here at last is something definite. No, not even now ; for these will, at least, claim their young housefly, and their full-grown house-fy, and expect you to believe that late in the year their house-fly takes to biting you, little dreaming that the little fly, and the big fly, and the fly which bites you, not only are different species but even belong to different genera; that the little fly never grows big, that the big fly never was little, and that their house-fly could not bite you if he would. What, then, 